\title{
Children's rights law and human rights law: analysing present and possible future interactions
}

Eva Brems, Ellen Desmet and Wouter Vandenhole

\section{Introduction}

This volume explores whether and how children's human rights law and other branches of international human rights law can inspire and enrich one another. Children's rights law is often perceived and studied in isolation from the broader field of human rights law. This book examines to what extent this results in lost opportunities for children's rights law as well as for general human rights law. Children's rights law has a number of allegedly distinctive characteristics, such as the use of general principles, the emphasis on the 'best interests of the child', and the inclusion of 'third parties' (e.g. parents) in the Convention on the Rights of the Child (CRC). The question arises whether these features could be a source of inspiration for general human rights law or other categorical branches of human rights law. This is explored in the first part of the volume. The second part reverses the question: could children's rights law draw inspiration from developments in other branches of human rights law that focus on specific categories of rights holders, such as women, persons with disabilities, indigenous peoples, or older persons? Finally, the interaction between children's rights law and human rights law - and the potential for isolation, inspiration or integration - may be coloured or determined by the thematic issue under consideration. Therefore the third part of the book studies the interplay between children's rights law and human rights law in the context of specific topics: intra-family relations, LGBTI marginalization, undocumented migration, media, the right to a healthy environment, and human rights obligations of business.

For the purposes of this volume, the editors understand the term 'integration' to refer to a deliberate effort from one branch of international human rights law to incorporate concepts, methods or practices that originate from another branch of international human rights law. The term 'inspiration' refers to cases in which direct incorporation of concepts or practices from another branch of international human rights law is not considered appropriate, but where some ideas or dynamics in one branch have nevertheless influenced or could influence ideas or 
dynamics in another branch. Another way of looking at the difference between 'integration' and 'inspiration' is that it is a matter of degree: 'inspiration' indicates light or indirect forms of influence, whereas 'integration' is used for more far-reaching and/or more direct forms of influence. In this sense, 'integration' may come down in certain cases to an 'uncritical embrace', whereas inspiration may suggest a more critical, deliberated and possibly selective interaction. Finally, the term 'isolation' is used to indicate a (deliberate or not) disregard of what is going on in other branches of international human rights law.

\section{Inspiring other human rights regimes}

The first part of the book examines the possible wider relevance of the most salient characteristic features of children's rights law, for both general human rights law and other categorical branches of human rights law. In a first, umbrella chapter, Vandenhole identifies and examines five allegedly distinctive characteristics of the CRC: (i) the indivisibility of civil, political, economic, social and cultural rights; (ii) the inclusion of new substantive norms and elements, particularly as regards non-discrimination, the right to life, the concept of evolving capacities, and the right to education; (iii) the 'best interests of the child' concept; (iv) the use of general principles; and ( $\mathrm{v}$ ) the incorporation of 'third parties' as duty bearers in addition to the domestic state. He shows, among others, that some of these features have either never been (e.g. indivisibility) or are no longer (e.g. general principles) unique to children's rights law. The following chapters discuss three of these characteristics - arguably those that have been most widely invoked and discussed in children's rights practice and scholarship - in more depth: the best interests of the child (Stalford), the use of general principles (Lundy \& Byrne) and the inclusion of third parties in the CRC (Ruggiero, Volonakis \& Hanson). The authors analyse the historical and legal basis of these features, their current use in children's rights law and beyond, and their potential future contribution to general human rights law and other specific areas of human rights law. The concept of 'third parties' is approached differently in the two chapters: whereas Ruggiero et al. focus their analysis on parents as third parties in the CRC, Vandenhole looks more broadly into non-state actors and extraterritorial obligations. 
The overall assessment of the possible added value of these three features for other domains of human rights law runs rather parallel between the four authors. No calls for a direct integration or transplant of one or more of the features in other areas of human rights law are formulated. The potential for fruitful inspiration is appraised differently for each of the three characteristics. Most reluctance is expressed as regards using the best interests principle with respect to adult rights holders. Vandenhole and Stalford caution against 'any naïve transplant' and 'extending the best interests too readily to other decision-making contexts' respectively. The relevance of general principles for other branches of human rights law is more positively assessed, yet also in a qualified way, as contributors point to the weak legal and moral basis of general principles in children's rights law (Vandenhole), and propose a set of criteria that could guide the identification and use of such principles (Lundy \& Byrne). Finally, the inclusion of third parties as duty holders is evaluated as holding most promise for influencing other branches of human rights law, a conclusion that is supported both by an analysis of the rights, duties and responsibilities of parents in the CRC (Ruggiero et al.) and by an examination of the questions surrounding non-state actors' and extraterritorial human rights obligations (Vandenhole).

Two categorical human rights regimes are explicitly mentioned as possible candidates to be 'inspired' by children's rights law: the rights of persons with disabilities and the emerging regime on the rights of older persons. The Convention on the Rights of Persons with Disabilities (CRPD) has already drawn inspiration from children's rights law, namely by codifying a list of general principles in its Article 3 (as discussed by both Lundy \& Byrne, and Vandenhole). In the view of Lundy \& Byrne, the principles in the CRPD are too numerous (eight) - 'so all-encompassing that they become dilutionary' -, which risks impeding their effective functioning. They prefer the CRC Committee's approach, where the more limited number of principles (four) allows 'for a substantive and focused body of work to develop over time' - an approach that also better fits the reality of limited resources of the UN treaty bodies. Forward-looking, Ruggiero et al. suggest that disability rights law could learn lessons from children's rights law when developing its approach to third parties, limited in the CRPD to a reference to 'families and caregivers' as an additional target group of state measures to prevent exploitation, violence and abuse, next to persons with disabilities themselves (Article 16, 2). In order to conceptualize the legal position of these families and caregivers, the authors propose that the concept of 'responsibilities' might offer a useful point of departure, influenced by the way 'parental responsibilities' have become 
understood in children's rights law as 'limited and functional rights aimed at the fulfilment of the rights of the child'. The older persons' rights regime could, in their view, equally benefit from this concept of 'responsibilities', if third parties are included in its legal framework. The rights of older persons are also mentioned by Vandenhole as an instance where developing a set of general principles could be usefully envisaged. ${ }^{i}$ Stalford does not single out particular categorical regimes of human rights as possible destinations of inspiration, and instead discusses the possible application of 'best interests' in relation to adult human rights in general. She does describe, though, how the concept has been used (and abused) 'in a clinical health care context for adults deemed to lack capacity to make decisions for themselves'.

The remainder of this section succinctly reviews the arguments put forward by the authors in favour of and against a broader (adapted) use of best interests, general principles, and the inclusion of third parties.

\section{Best interests}

Stalford and Vandenhole both note that applying best interests in respect of other so-called vulnerable groups of rights holders seems appealing at first sight. Nevertheless, they warn against a too ready appropriation of this concept in adult human rights contexts, on the basis of various arguments. Both authors refer to the already opaque and indeterminate meaning of the concept in children's rights law, which leads to inconsistent and even opposing outcomes - something which would risk to be exacerbated if best interests were broadened towards other human rights domains. In addition, Stalford emphasises the child-specificity of the concept, in three ways: it serves to make children's interests visible in an adult-dominated world; it offers a way to address possible clashes between interests of adults and the interests of the child; and - from a utilitarian perspective - paying attention to the child's best interests enhances general societal welfare. This conceptualisation of best interests makes it difficult, she argues, to extend its application to the realm of adult rights holders. Such an extension could lead, in the words of Parker, to 'an artificial and sterile universalism', dissolving the distinctiveness of the concept. Moreover, Stalford cautions that broadening the use of best interests could undermine the concept's original objective, of protecting children's welfare. Such extension also risks 'entrenching a predominantly paternalistic model of best interests from which, for many years now, activists have been trying to extricate children's rights'. Finally, Vandenhole and Stalford seem to differ in 
their view of the weight to be given to the best interests of the child (as prevailing or as (only) carrying greater weight in a balancing exercise). Whereas Vandenhole points to a lack of clarity on this issue, for instance in the jurisprudence of the European Court of Human Rights, for Stalford it is clear that best interests do not imply a trump card for the interests of the child, but that they accommodate the rights of adults. Albeit on the basis of a somewhat different argumentation (unclear weight versus inherent consideration of adult rights), the conclusion of the two authors is similar, namely that this argumentation provides another reason why transposing best interests to other human rights regimes does not seem desirable.

General principles

Tracing the history of the identification of the general principles by the CRC Committee, Lundy \& Byrne disclose the difficulty of finding a logical explanation of why precisely Articles 2, 3, 6 and $12 \mathrm{CRC}$ were elevated to the status of general principles. Vandenhole also points to the weak legal and theoretical grounding of the principles, and the fact that the principles of nondiscrimination and participation are not child-specific. Notwithstanding their fuzzy origin, Lundy \& Byrne show how the general principles have been predominant in children's rights implementation efforts by state parties and other duty bearers, in advocacy by NGOs and civil society, and in academic scholarship. Although the general principles thus seem to have contributed to an enhanced understanding and acceptance of the $\mathrm{CRC}$, the authors point out that the key role attached to the general principles may also have led to a reduced attention for other substantive treaty provisions. To assess the added value of the concept of general principles, Lundy \& Byrne then proceed to investigate other human rights treaties, adopted prior to and after the CRC. Although they identify provisions in the Convention on the Elimination of All Forms of Discrimination against Women $(\mathrm{CEDAW})^{\mathrm{ii}}$ as well as in the International Convention on the Elimination of All Forms of Racial Discrimination that could serve as general principles, they also wonder 'what if anything has been lost in their absence'. For it can be argued that the lack of general principles has not considerably impacted the implementation of both treaties. On the other hand, as already indicated above, the actual inclusion of general principles in the CRPD does not seem to make a substantial contribution to the convention's implementation either. In their conclusion, Lundy \& Byrne formulate some criteria that could guide the identification of convention-specific general principles, including the criterion that the principle has a 'clear basis 
that enables [it] to apply across the other substantive provisions of the Convention and to do so in a way that enhances implementation', and the criterion that the principle 'addresses a barrier to the realisation and/or a route to fulfilment of the rights of the protected groups and individuals'. Moreover, they submit that the 'sum of the principles must ... be greater than the parts'. Lundy \& Byrne and Vandenhole thus concur that, when carefully selected and well grounded, general principles are an interesting feature of children's rights law that could inspire other human rights fields.

\section{Inclusion of third parties}

A final distinctive characteristic of the $\mathrm{CRC}$ is that it breaks through the traditional binary relationship in human rights law of individual rights holders versus the state, by introducing 'third parties' - more specifically parents and caregivers - as holding 'rights, duties and responsibilities'. On the basis of their detailed analysis of the status of parenthood in the CRC, Ruggiero et al. identify some advantages and risks of including third parties in other human rights regimes. Two arguments plead against such inclusion. First, bringing in third parties may lead to controversy and polarization, as the authors illustrate with their account of the dichotomous nature of the relationship between parental rights and children's rights in the United States. Such 'dichotomous vision consistently downplays the contentious nature of the relationship between the family and the State'. Second, it has been argued that the triangular relationship in the CRC has led to obscuring the legal obligations of states parties as regards the rights of the child. Critics of the campaign against corporal punishment have argued that this campaign allowed states to hide their direct obligations to combat structural economic inequalities, by shifting the responsibility onto parents. On the other hand, Rugierro et al. suggest that other human rights regimes - in particular the rights of persons with disabilities and the rights of older persons could draw inspiration from the 'conciliatory perspective' as adopted in the CRC, 'which prescribes that a balance needs to be made between the rights of different actors involved by distributing responsibilities, duties and rights among parents/caretakers and the State towards the promotion and realization of an abstract public good, i.e. the child's well-being'

Vandenhole draws other, yet complementary conclusions from the inclusion of third parties in the CRC. In his view, the reference to parents in the CRC may contribute to 'opening up the dutybearer side of human rights law, in order to include other actors than the state'. He pleads for a 
more consistent use of terminology though, to indicate the legally binding nature of a certain norm, and warns that the relationship between the obligations and responsibilities of the various actors should be further clarified. Secondly, the multiple references in the CRC to international assistance and co-operation indicate that the CRC goes beyond the domestic state as the only statist duty-holder. As regards the conceptualisation of the responsibilities and obligations of nonstate actors as well as of extraterritorial obligations of the domestic state, Vandenhole regrets, however, that the CRC Committee has not yet fully developed this potential. He refers to the work of the Committee on Economic, Social and Cultural Rights (CESCR) as a possible source of inspiration for children's rights law in this respect. The CESCR is not the only human rights treaty body from which children's rights could learn, though, as is explored in the second part.

\section{Learning from other categorical human rights regimes}

The chapters in part two look into other categorical human rights regimes - women's rights; rights of persons with disabilities; indigenous peoples' rights; and rights of older persons, in order to examine how these regimes may inspire the human rights of children (and vice versa).

The authors were asked to have their chapters guided by two sets of questions, the first more analytical, the second more normative:

(i) What are distinctive characteristics of the human rights protection of the category of rights holders under consideration? What are best practices? What are pitfalls to be avoided?

(ii) Which general lessons may be drawn from these (sub)disciplines about the protection of the human rights of a specific group? Which aspects may inspire the development of children's rights law specifically?

In the course of this exercise, it became clear that challenges may be common to the categorical regime under scrutiny and children's human rights (that is in particular the case with regard to rights of indigenous peoples), or that children's rights may be a more prominent source of 
inspiration for other categorical regimes (under construction), as the experience with the rights of older persons seems to suggest.

In what follows, we will look into the most salient distinctive characteristics of each of the three categorical human rights regimes under scrutiny, and draw some inspirational conclusions for children's rights law.

A preliminary caveat is in order, though. The distinctiveness of categorical human rights regimes for women, persons with disabilities, indigenous peoples and older persons must be put into perspective: as Brems points out, all are considered as vulnerable groups and all face the challenge of balancing protection with emancipation or independence. Moreover, intersectionality rather than a particular unique status seems to really matter in practice. So while some of the categorical human rights regimes may have unique characteristics, they are all emancipation rights, Brems submits in her chapter on women's rights, that address similar challenges. What unites emancipation rights is that they strongly matter in horizontal relations and require cultural change. The realisation of such a 'cultural' paradigm shift seems most challenging where children are concerned: other categories of so-called vulnerable persons demand that they are not treated like children, hence reinforcing the stereotypes of vulnerability and incapacity that tend to dominate in discourse on children. ${ }^{\text {iii }}$ An interesting avenue for further research on emancipation rights may be the area of work. Whereas the right to work (in dignity) has made quite some leeway with regard to women, persons with disabilities and older persons, developments with regard to children are going in the opposite direction of a ban on all child labour, rather than of the recognition of the right to work in dignity. Indigenous peoples' rights lend support to defining childhood not only in terms of biological age, and in this way possibly too to the recognition of children of a right to work in dignity.

Women's rights together with indigenous peoples' rights seem the most different regimes among these emancipation rights. The commonalities of children's rights, rights of persons with disabilities and rights of older persons indeed stand out in the analysis of these respective regimes: for example, for all three, the debate on capacity rages on, whereas with regard to women's rights and indigenous peoples' rights, the capacity debate seems over. Children's rights, rights of persons with disabilities and rights of older persons face a fluid delineation of the 
category they are covering. Admittedly, the latter characterizes indigenous peoples' rights as well, whereas it is pretty clear who are considered 'women'. iv Brems points out: 'The emancipatory challenge of children's rights lies in making people see not only children's inherent vulnerability, but also their inherent capacity for autonomy, and the gradual development of that capacity. In that sense, children's rights as emancipation rights are both similar to and different from women's rights as emancipation rights.' (Chapter 5, this volume).

Let us now turn to some of the most salient particularities in comparison to children's rights, of each of the categorical regimes under scrutiny.

\section{Women's rights}

The women's rights regime may well be the area where the problematic nature of protection dynamics has been most clearly exposed and addressed. As Brems points out, the 'emphasis on vulnerability and protection [is seen] as an expression of paternalism that reinforces gendered stereotypes and that contributes to denying women equal opportunities.' (Chapter 5, this volume). In the struggle for realizing women's rights as human rights, the emphasis is much more on empowerment and autonomy, and hardly on vulnerability. Protective measures for children have not been delegitimized to the same extent; to the contrary, the very success of children's rights seems to be grounded in the generalized perception of children as vulnerable and the widespread support for maximum protection of children. So, in challenging this myopic emphasis on children's autonomy, children's rights may benefit from women's rights. The need to bring about cultural change to address stereotypes or prejudices, means that action has also to be taken in horizontal relations. Brems believes that this is the key learning point for children's rights: cultural perceptions of and practices towards children need to be de-normalized, which necessitates the inclusion of a specific provision on the state's obligation to work for cultural change similar to the one in article 5 (a) CEDAW. Such a provision should function as a selfstanding obligation, but also as an additional general principle that guides the interpretation of all CRC provisions. A cue could be taken from the work on harmful cultural practices, but efforts should extend far beyond that set of cultural practices. 
Rights of persons with disabilities

While acknowledging that in a pessimistic reading any innovative aspect of the CRPD may be repudiated at the general level and in the particular context of the rights of children (with disabilities), Sandland mainly emphasizes the major shift in the CRPD's underpinning model or paradigm. The CRPD is premised on a holistic social model of disability. The shift to a social model of disability (whereby disability is not seen as an inherent deficiency, but rather as the result of the interaction between persons with impairments and attitudinal and environmental barriers, see the Preamble to the CRPD) echoes very much the need for cultural change as argued by Brems. But both authors (and possibly both fields) disagree on the extent to which developments in their own field could or should be paralleled in children's rights. Brems emphasizes the persistent difference between women's rights and children's rights. She argues that 'the majority of children have a capacity for autonomy that is significantly lower than that of adults', and that '[t]aking children's capacity for autonomy seriously also means recognising the limits of that capacity.' The optimal balance between protection rights and autonomy rights will therefore differ for women and children. In disability law, the role that the concept of 'capacity', and third-party decision-making in the 'best interests' of persons found to 'lack' capacity used to play, may be argued to have been replaced. Through the notion of supported decision-making, the assumption now prevails that capacity to make one's own decisions is always attainable, if the person with disability is given the necessary assistance.

Sandland submits that the rights of persons with disabilities raise 'questions regarding the continued viability of an essentialist, status-based, non-socialised, construction of children and their rights lack of any comparable "social model of childhood", and invites to ponder about the effects of a 'social model of childhood'. For one, such a social model of childhood would challenge 'the continued desirability of a role of 'capacity' and 'best interests' as mechanisms for making decisions in relation to children' (Chapter 6, this volume). In other words, the

CRPD raises the questions of whether (i) it is not now time to shift from a status-based to a functionality-based understanding of the limitations that simply being a 'child' as a matter of legal status places on a young person in terms of their abilities to make decisions for themselves, and; (ii) there should be, if not an abandonment of the best interests principle, then at least the severance of that principle from a substituted 
judgement framework for those children found to have functional capacity and its attachment instead to a supported decision-making model. (Chapter 6, this volume).

The CRPD also adopts a holistic approach to rights, which entails the undermining of traditional divisions within orthodox human rights discourse between types of rights (in particular civil and political versus economic, social and cultural rights). The typology impacts the general obligation incumbent on States: the former are to be realised immediately, the latter only progressively subject to the availability of resources. In Sandland's view, the CRPD constructs 'civil and political rights as being interwoven with economic, social and cultural rights', and thereby 'understands the legal subject as being interdependent and relational': 'we all need effective economic, social and cultural rights if we are truly to be able to exercise our civil or political rights.' This approach 'undermines the liberal legal subject, seen in political and civil rights terms as being independent, isolated and autonomous.' (Chapter 6, this volume). Although this comprehensiveness, as it has been called in children's rights literature, has also been identified as characteristic of children's rights, the CRPD seems to push it to a higher level, and children's rights may learn from this.

Finally, Sandland identifies some new rights, and the extension and reconfiguration of existing rights for children (with disabilities): e.g. the evolving capacities of the child and the right to participate effectively in society may have been elevated to general principles; the right to physical and mental integrity is explicitly recognized and the right to life better protected; and the right to physical and mental integrity may provide leverage for access to all spaces open to the public, including private spaces.

Indigenous peoples' rights

Desmet identifies three areas in which children's rights may learn from indigenous peoples' rights: space for flexibility in the definition of the group; the consequences of romanticised constructions; and interpretative guidance for participation and consent.

The field of indigenous peoples' rights uses flexible conceptions of indigenous peoples, with selfidentification as a central element. The CRC on the other hand employs a static definition of children. However, children grow up in very diverse geographical, cultural and socio-economic 
contexts. A general upper age limit at eighteen is quite Eurocentric, and may negatively affect certain rights of children, such as a right to work in dignity. Desmet therefore pleads for a multidimensional understanding of children, which does not exclusively focus on chronological age; but also take into account self-identification as well as psychological and contextual factors.

Secondly, indigenous peoples and children may be said to have been constructed in a similar way, from historically marginalized to romanticised and idealised today. The romanticised constructions of indigenous peoples and children may have a negative impact on rights protection, and may moreover lead to a lack of critical scientific analysis. Desmet challenges these essentializing tendencies and calls for an increase in efforts 'to unveil assumptions and constructions that essentialize indigenous peoples and children, as well as the impact of these constructions on research, policy and practice.' (Chapter 7, this volume).

Thirdly, notions of consultation and consent are legally well-developed in the field of indigenous peoples' rights. Indigenous peoples' rights can inspire children's rights law in furthering the theoretical, legal and practical development of the collective dimension of the right of children to be heard (including aspects of representation), and in fleshing out the attributes of the emerging right of children to consent (namely free, prior and informed).

\section{Rights of older persons}

The field of rights of older persons is the only one where intersectionality is excluded: children can never belong to this category while being children. Moreover, the codification of the human rights of older persons is still in a rather early stage (no treaty has as yet been adopted), which may explain why the question of inspiration is more prominently in the reverse direction, i.e. which learning points does the CRC contain for the rights of older persons. In Chapter 8, Habbig, Hoefmans and De Hert suggest three points of inspiration. First of all, the paradigm shift that we discussed earlier (from vulnerability to autonomy), although not fully realized in the CRC, is clearly also relevant to address the stereotypes associated with ageing. Moreover, and quite typical of the CRC, the use of principles in addition to rights is believed to be a good practice. Thirdly, the concept of evolving capacities and the retreating role of parents or other caregivers may be of relevance to the rights of older persons, although it cannot be simply transplanted: whereas children gradually develop 'towards full capability in decision-making, older persons 
often see a reverse development.' But the key questions are similar: how to balance and facilitate as much autonomy as possible while growing more dependent? And how to define the evolving role, responsibilities and obligations of informal and formal caregivers?

Children's rights may learn from the older persons' rights regime, as they could from the indigenous peoples' rights regime, how to use a more variable age limit: whether a person is labeled as 'aged', 'old' or 'elderly' depends on the cultural context, economic considerations and the respective life expectancy, and such a more open-ended approach could be beneficial for children's rights too.

Although too early to tell, the authors express the hope that if the older persons' rights regime 'strikes the right balance between protection and emancipation, this could be an argument to look more closely at the parallel debate in children's human rights law', in particular with regard to the right to work.

Finally, age-based discrimination has been developed within the older persons' rights regime, but remains by and large a blind spot in children's rights law. The prohibited ground of age is conceptually not yet well developed in children's human rights law, and may benefit from developments within the older persons' rights regime.

In sum, all five regimes are part of a struggle for emancipation. Women's rights and disability rights seem to have been most successful in introducing a paradigm shift, away from protectionism to a better acknowledgement of autonomy. Authors disagree though whether children's rights should make a similar shift, towards recognition of full capacity of children, and a supported decision-making model, as one reading of disability rights suggests. Disability rights may also be most inspirational in intertwining civil and political rights, and economic, social and cultural rights, and hence in imposing immediate obligations with regard to economic, social and cultural rights. Indigenous peoples' rights and rights of older persons have adopted a flexible notion of the category concerned, which may inspire children's rights to move beyond a one size fits all approach to the upper limit of 18. Finally, more explicit engagement with age discrimination may sophisticate the children's rights regime. 


\section{Situating children's human rights vis-à-vis general human rights in concrete contexts}

In the third part of the book, authors zoom in on a thematic area, to examine the interplay between children's rights law and human rights law. They describe the state of affairs as to the relation between children's rights law and human rights law in the particular thematic area. More specifically they look for signs that mark this relationship as one of either 'isolation', 'inspiration' or 'integration'. In the concrete reality of a specific field, does it seem that children's rights law impacts upon general human rights law or vice versa? In addition to these analytical questions, authors were asked to ponder also some normative questions: what are promising or desirable avenues for further development of the role of children's human rights law vis-à-vis general human rights law in this thematic issue? Should there be isolation, inspiration or integration, and if so, how?

The thematic areas that are examined in this manner are family relations (Chapter 9), LGBTQI marginalization (Chapter 10), undocumented migration (Chapter 11), media (Chapter 12), environmental protection (Chapter 13) and corporate responsibility for human rights (Chapter 14). From a normative point of view, all chapters argue in favour of increased inspiration or integration between children's human rights and other field of human rights law, with some stating that children's human rights should borrow certain elements from other human rights fields, and others claiming that other fields would do well to learn from developments in children's human rights law or to include a focus on children's rights in future normative development.

\subsection{Enriching children's rights with insights and concerns from other human rights fields}

Focusing on the family sphere, Titia Loenen examines (in Chapter 9) how much credit CEDAW and CRC give to each other in this sphere. Loenen is satisfied that CEDAW provisions pay adequate attention to children's rights through explicit references to the 'best interests of the child principle'. Yet she assesses the limited attention to gender in the $\mathrm{CRC}$, including in the work of the CRC Committee, as insufficient. The CRC Committee is integrating a gender concern by introducing a regular mention of the 'girl child'. Yet where parents are concerned, the CRC Committee is generally mute on gender, and prefers the use of gender-neutral language. Loenen draws our attention to the fact that challenging the gender stereotypes and gendered role patterns 
in the family holds a central position in the CEDAW's theory of change toward gender equality. Indeed, the CEDAW Committee 'links the gendered division of family roles with the overall inferior position of women in society, their economic dependence, poverty and lack of social, economic and political power' (Chapter 9, this volume). For Loenen, the fact that the CRC emphasizes the shared responsibility of parents for the upbringing of their children is not sufficient. In addition, she states that the CRC Committee should explicitly address the gendered dimensions of this shared responsibility. By recognizing that women are often the primary caretakers of children, the CRC could, according to Loenen, contribute to the empowerment of women. At the same time she notes that where the CRC and its Committee do pay specific attention to parents' gender, i.e. in the context of motherhood as a biological function, this sometimes results in the instrumentalisation of women, as their interests seem to be subordinated to those of children. Interestingly, Loenen points at a procedural approach that may be best practice in terms of human rights integration: the joint General recommendation/General comment of the CEDAW Committee and the CRC on harmful practices integrates a women's rights approach and a children's rights approach in a manner that Loenen considers optimal.

Women's rights and their focus on relations within the family are a long-standing theme in human rights law, amongst others because the adoption of CEDAW predates that of the CRC with a decade. Loenen's argument is therefore for the integration within children's rights of the specialized knowledge and experience of a mature specialized system and its expert body. On the other hand, Ivana Isailovic' chapter on children's rights in relation to LGBTI marginalisation (Chapter 10) argues for the integration in children's rights of novel rights protection standards that have only partially gained full recognition in international law as binding standards. Indeed one can imagine a future LGBTI rights regime comparable to the specialized human rights regimes for women, children, persons with disabilities etc. Yet for now, LGBTI rights as international human rights are found mostly in soft law and in the jurisprudence of supranational monitoring bodies. Isailovic points out that, on account of their initial focus on sexuality, LGBTI rights have long been conceptualized as adult rights, and the emergence of children in this landscape is a recent development. Until recently, children's rights have been mobilized mostly to counter LGBTI rights. Yet today, the CRC Committee is starting to address LGBTI rights in its General Comments and Concluding Observations. Isailovic' central argument is that the CRC's potential to protect the rights of LGBTI children or children raised by LGBTI parents may 
or may not be realized depending on the willingness to embrace new interpretations of CRC provisions. Such new interpretations would have to take into account soft law such as the Yogyakarta Principles as well as interpretations of other human rights instruments that do justice to the experiences of LGBTI individuals. Isailovic builds this argument through three cases: selfdetermination rights of intersex children under article $12 \mathrm{CRC}$, the interpretation of 'the best interests of the child' (article $3 \mathrm{CRC}$ ) in family life cases, and addressing bullying, intimidation, and negative stereotypes in the school context under article 29 CRC.

\subsection{Enriching other human rights fields with insights from or a focus on children's rights}

The chapters by van Kalmthout on environmental rights (Chapter 13) and by Erdem Türkelli on business and human rights (Chapter 14) likewise discuss dynamic and highly topical fields of human rights law in which normative development is still ongoing. Yet contrary to Isailovic, they argue not for the integration of general human rights law developments into children's rights, but instead want children's rights to be taken on board in the development of general human rights law.

For Erdem Türkelli this point of view is based on the finding that, in the area of business and human rights, recent children's rights (soft law) instruments have been developed that have been strongly inspired by general soft law instruments in this field. Indeed, both the Children's Rights and Business Principles and the General Comment 16 of the CRC Committee are heavily inspired by the UN Guiding Principles on Business and Human Rights (UNGP). What is more, the CRC Committee's General Comment goes further in that it corrects or 'improves' the UNGP from a children's rights point of view. In that respect, one might argue that what Isailovic would like to see happen in the field of LGBTI rights, i.e. the reinterpretation of children's rights in line with recent developments in a specific field of general human rights, has in fact happened in the area of business and human rights. Yet Erdem Türkelli deplores the fact that the operationalisation of both frameworks takes place in isolation from one another. The main discussion - in particular on a potential future binding treaty- takes place in the general human rights framework, and 'the momentum on children's rights and business has not yet been translated into a tangible integration of children's rights into the broader human rights discussions on transnational 
obligations in a meaningful way' (Chapter 14, this volume). This is why she argues that the trend should now be reversed, and that after the integration of business and human rights in the children's rights framework, children's rights should now be integrated in the general human rights frameworks addressing businesses.

In the field of environmental rights, discussed by Danielle van Kalmthout, developments that may lead to the recognition of a binding human right to a healthy environment, have so far not sufficiently included children's specific protection needs. Van Kalmthout therefore argues in favour of integrating children's needs and interests in these debates. Yet, contrary to Erdem Türkelli, her vision is not one in which children's rights would be incorporated in a general instrument or provision. Instead, for van Kalmthout the integration of children's rights in the debates about a right to a healthy environment, should lead to the separate recognition - in the context of the $\mathrm{CRC}$ - of a child right to a healthy environment in addition to a general right to the same. In her analysis of the CRC, van Kalmthout identifies numerous provisions that have been interpreted to include some aspects of a child right to a healthy environment and/or that might be interpreted in a way that would help shape such a right. Yet - and in this her position differs from that of Isailovic- she does not consider reinterpretation a satisfactory solution. In addition to looking for the strongest possible guarantees, this position may in part be motivated by the importance of the symbolism of recognition that a separate provision can deliver.

Both Erdem Türkelli and van Kalmthout conceive of the integration of children's rights in general human rights as a way of providing better protection for the human rights of children. Other authors have however argued that certain interpretations that have been developed in the context of children's rights, may serve as an inspiration to improve general human rights for all, including adults. This line of argument is developed in the chapters on media and undocumented migration.

In Chapter 12, Eva Lievens analyses in detail how the European and UN human rights regimes approach children as consumers, participants and subjects of the media. The combination of hard law, soft law and the interpretations of supranational human rights bodies, results in a very sophisticated regime. Built mainly on three CRC provisions (arts 12, 13 and 17) it is a threedimensional approach, including protective measures, in addition to obligations to provide, as well as an emphasis on participation. This is a much richer framework than the general human 
rights framework that applies to adults in relation to the media, and that includes mainly negative rights. Lievens therefore argues that adult rights holders could benefit from enhanced human rights protection, if the children's rights regime on the media were to inspire the general human rights regime in this field. In addition to positive state obligations, this would entail a right to participate in media governance processes. Moreover, the multi-stakeholder approach of children's rights - conferring responsibilities not only on the state, but also on parents and the media- could prove a useful model to concretize in human rights terms the responsibilities of 'third parties' in the media sector, 'such as journalists, internet service providers, search engines or social network site providers' (Chapter 12, this volume).

The analysis of Julie Ryngaert and Wouter Vandenhole of the use of 'vulnerability' concepts in the context of the rights of undocumented migrants (Chapter 11), likewise reveals the potential of sophisticated rights reasoning that was developed for children's rights, to have broader application. The concept of vulnerability is mobilised in both children's rights law and general human rights law to single out individuals or groups that need enhanced protection or priority treatment. In general human rights law, children are often considered more vulnerable than adults in this context. The detailed analysis of Ryngaert and Vandenhole shows that the vulnerability concept that is applied (though not always) by the CRC Committee is significantly more sophisticated than that which is used by general supranational human rights bodies, in particular the European Court of Human Rights. The sophistication concerns the combination of vulnerability and autonomy, a contextual understanding of vulnerability, and attention to diversity within children as a vulnerable group. Ryngaert and Vandenhole argue, on the basis of empirical studies, that the CRC Committee's nuanced vulnerability approach is more suitable for application to the rights of undocumented migrant children than the European Court's approach. This is because each of the nuances introduced by the CRC Committee reflects the reality of undocumented migrant children. Ryngaert and Vandenhole however do not simply make the argument that the CRC Committee has more expertise on children's rights and experiences than general human rights bodies, and that therefore general bodies 'doing children's rights' should model their approach after that of the CRC Committee. Instead, they argue, again with empirical support, that the CRC Committee's nuanced vulnerability approach is also better suited for addressing the human rights of undocumented migrant adults. They claim that this is a less reductionist approach that better reflects the humanity of undocumented migrants. An additional 
benefit of this approach, they argue, is that it does away with the dichotomy that pitches undocumented migrant children and their rights against adults (who may even be their parents) in the same situation. In Ryngaert and Vandenhole's interpretation, what may at first sight seem to be a distinctive feature of children's rights protection, is reframed as a state-of-the-art interpretation of general human rights, which happens to be developed in the context of children's rights.

\subsection{Reasons for pro-integration viewpoints}

Across chapters, the main reasons for normative positions in favour of increased inspiration or integration between children's human rights law and general human rights law or other specific 'branches' of human rights law, are threefold: increasing rights protection, improving rights protection, and doing away with conflicts between the human rights of children and adults.

Increased rights protection for children is the main driver of van Kalmthout's argument: the movement toward formal recognition of a binding right to a healthy environment should, in her opinion, equally lead to the recognition of a parallel children's right. The reason is simple: it has been shown empirically that children suffer more than adults from environmental degradation. Hence, children need enhanced environmental rights protection.

Increased rights protection for both adults and children is what Loenen and Isailovic are after. Loenen aims to enlist the CRC's assistance for the realisation of one of the central missions of CEDAW, which is the elimination of harmful gender stereotypes and role patterns. This approach seems to proceed from an integrated view of human rights that endorses an 'all hands on deck' approach, in which specialized human rights systems should avoid a narrow focus on their area of special interest, but should instead also strive to contribute to optimal human rights protection overall. Isailovic is dealing with a topic that is in the frontline of the dynamic development of international human rights law. Injustice done to LGBTI individuals is finally being recognized and brought under the label of human rights violations. While this process is still not completed, and is also encountering resistance, Isailovic has a vision in which the focused attention for LGBTI rights in specialized instruments goes hand in hand with their mainstreaming in other 
fields of human rights. Children's rights are particularly salient in this respect for several reasons, which include the vulnerability of LGBTI children, the importance of educating the younger generation if one wants to generate a change of minds, and finally the abuse of children's rights by those who object to LGBTI rights.

Improved rights protection for children or for all as a goal of human rights integration, can refer to the objective of avoiding negative side effects of current -'un-integrated'- developments in human rights law. In that vein, Ryngaert and Vandenhole propose that general human rights law improves its concept of vulnerability in relation to undocumented migrants so as to avoid reductionism, stigmatisation and disempowerment that may be the by-products of an unnuanced focus on vulnerability. Likewise, Erdem Türkelli proposes integration of children's rights into mainstream debates on business and human rights, to bypass the undesirable effect of the opposite movement, which had resulted in isolating 'children's rights and business' from the momentum on human rights and business. Even without the identification of undesirable sideeffects of the current regime, a comparison with children's rights may lead to identifying sophisticated arguments or concepts that can improve general human rights. In the media context, Lievens identified participation rights and the multi-stakeholder approach as promising features of the children's rights approach in this regard.

Finally, several authors conceive of the integration between children's rights and general human rights as a way of appeasing tensions between the rights of children and those of adults. Loenen points out that the CRC Committee instrumentalizes biological motherhood at the service of children, disregarding the interests of mothers. In her vision, an integrated approach in which the CRC Committee strengthens its gendered analysis would avoid such statements as a blanket recommendation for mothers to breastfeed their children between 6 and 24 months without considering the implications for the women concerned. An integrated approach would thus not automatically favour one side in a situation that is characterized by conflicting rights claims, but rather attempt to reconcile both. In other situations, what appears to be a tension between rights of adults and those of children, may disappear as a result of the adoption of an integrated rights approach. Ryngaert and Vandenhole argue that the adoption of a nuanced vulnerability concept for both adult and minor undocumented migrants would deconstruct the dichotomy between the two categories that now leads to different rulings on children and adults in similar situations. In 
the field of LGBTI rights, Isailovic argues that integration of LGBTI rights thinking in the interpretation of children's rights would dissolve false conflicts between children's rights and LGBTI rights that have often functioned as obstacles to LGBTI rights recognition.

\section{Conclusion: looking beyond}

Following the development of different categorical and thematic human rights regimes, human rights scholarship has become increasingly specialised and departmentalised. Academics too rarely look beyond their niche of expertise.

This book shows, however, that much can be learnt from taking off our blinkers and widening our gaze. Realising human rights - both in general and with respect to particular groups - may be well served by analysing more in depth the conceptual and practical developments in certain/other subfields of international human rights law. This does not imply that innovative concepts or distinctive approaches should be blindly transposed to other fields. It does mean that carefully analysing the benefits and drawbacks of the particularities of one human rights regime, may contribute to the enhanced effectiveness of human rights law as a whole and also lead to a more integrated experience of human rights.

It is the hope of the editors that this book will not 'remain in isolation', but inspire other scholars to ask similar questions from points of departure other than children's rights law.

\footnotetext{
This research has been funded by the Interuniversity Attraction Poles Programme initiated by the Belgian Science Policy Office, more specifically the IAP “The Global Challenge of Human Rights Integration: Towards a Users' Perspective" <www.hrintegration.be>.

${ }^{\text {i }}$ See also Habbig, Hoefmans \& De Hert, chapter 8 in this volume.

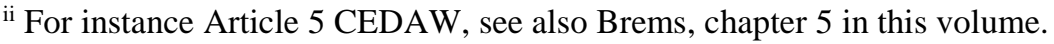

iii As Desmet points out, children have also been depicted as noble savages, which seems to show the persistence of stereotypes of indigenous peoples as well. She nonetheless demonstrates that the paradigm shift for indigenous peoples has been more or less successful. It may make sense, therefore, to better understand the reasons for that success, in order to realize a similar paradigm shift for children.

iv With the exception of intersex persons.
} 